\title{
Recommendations by health organizations for pulse consumption
}

\author{
Pascal Leterme* \\ Universidad Nacional de Colombia, Departamento de Ciencia animal, A.A. 237 Palmira (Valle) Colombia
}

\begin{abstract}
The present paper aims to study why and how health organizations recommend the consumption of pulses such as beans, chickpeas or lentils. Although it is recognized that frequent pulse consumption may reduce serum cholesterol levels and helps reduce risks of coronary heart disease and diabetes, these advantages are scarcely mentioned by health-promoting associations, i.e. vegetarians and organizations helping people to reduce the risks for chronic diseases. Pulses, especially common beans, are rather considered as whole grains that provide plenty of proteins, starch, dietary fibres, minerals and vitamins. Many organizations refer to the food guide pyramid to advise their members, and place beans either in the third part, together with meat, in the second one with fruits and vegetables, or in the bottom part with starchy foods. Whatever their place, they have acquired the status of staple food for anyone who wants to eat a healthy diet.
\end{abstract}

\section{Pulses: Consumption: Healthy food: Health organization}

\section{Introduction}

In developed countries, the demand for healthy foods is increasing fast. People are concerned by the possible consequences to health of genetically modified organisms and the mad cow disease epidemic. Nutrition is now health oriented, as attested by the abundant literature published in nutrition journals, websites and scientific books (Barasi, 1997; Mann \& Truswell, 1999).

In this context, pulses such as common beans, lentils or chickpeas, have encountered a revival of interest from the consumer. Once known as the poor man's meat, beans are now presented as a staple food for vegetarians, and most of the health organizations encourage their frequent consumption. They appear to help reduce the risks for coronary heart disease, diabetes and obesity, and significantly lower serum cholesterol concentrations (Geil \& Anderson, 1994).

The aim of the present paper is to study how healthpromoting associations present grain legumes and the benefits of consuming them. Most of the data of the study were obtained on the Internet website of these organizations because it was the easiest and fastest way to obtain the required information. When contacted, these associations often refer to their website anyway.

\section{Vegetarianism}

Although some vegetarians refuse to eat animal products for religious or philosophical reasons, the majority of them do so for health reasons. All the vegan and vegetarian associations promote vegetarianism as a good option for remaining healthy and avoiding metabolic diseases. They generally refer to the position taken by the American Dietetic Association about vegetarianism, in which the latter confirms that: 'appropriately planned vegetarian diets are healthful, nutritionally adequate and provide health benefits in the prevention and treatment of some diseases' (Messina \& Burke, 1997).

The vegetarian groups advise their associates on how to substitute meat products, i.e. animal proteins, by plant protein sources. The recourse to pulses is here obvious since the latter are, together with nuts and some seeds, the plant foods with the highest protein content. In the food guide pyramid for vegetarian meal planning, pulses, nuts and seeds replace the meat and fish products (Messina \& Burke, 1997; Vegetarian Society UK, 2001a). Pulses are first presented as protein sources that are cholesterol-free, virtually devoid of fat and good sources of dietary fibres, carbohydrates, calcium and iron (Mangels, 2001a,b; Vegetarian Resource Group, 2001; Vegetarian Society UK, $2001 b$ ). Although the Vegetarian Resource Group mentions a possible deficit in methionine for grain legumes, it considers that other protein sources eaten throughout the day will easily balance the diet (Mangels, 2001a).

The American Dietetic Association points out the following series of nutrients that may be of concern for vegetarians: calcium, iron, zinc, vitamins $\mathrm{D}$ and $\mathrm{B}_{12}$ and 
linolenic acid. Pulses are referred to as good sources of calcium, iron and zinc (Messina \& Burke, 1997; Mangels, $2001 b)$.

\section{Cancer}

In France, $36 \%$ of registered cases of cancer are located at the level of the digestive tract (de Puytorac, 2000). The American Institute for Cancer Research (AICR) estimates that eating a healthy diet, plus staying physically active and maintaining a healthy weight could cut the cancer risk by 30-40\% (American Institute for Cancer Research, 2001a). This association published a review based on more than 4500 research studies that examined the relationship between dietary factors and 18 specific cancers (American Institute for Cancer Research, 1997). The full report, entitled 'Food, Nutrition and the Prevention of Cancer: a Global Perspective' suggested 15 recommendations that help reduce cancer risk. The first proposes: 'choose predominantly plant-based diets rich in a variety of vegetables and fruits, pulses (legumes) and minimally processed starchy staple foods'. The fifth invites one to: 'eat 600-800 g a day of a variety of cereals (grains), pulses (legumes), roots and tubers'. The other recommendations concern the maintenance of weight, daily exercise, limitation of alcohol, meat, salt, fatty foods, etc. It is remarkable that pulse consumption is mentioned twice, including the first recommendation, making it a staple food in term of cancer prevention.

To popularize the concept of eating healthy, i.e. to prevent not only cancer but also obesity and diabetes mellitus, the AICR proposes the 'New American Plate', presented as a new approach to eating for better health and a model that emphasizes the kinds of foods that can significantly reduce the risk of disease. Plant-based foods such as vegetables, fruits, whole grains and beans should cover two-thirds (or more) of the plate. Meat, fish, poultry or low-fat dairy should cover one-third, or less (American Institute for Cancer Research, 2001b).

Harvard University's School of Public Health has also published a report in which it concluded that much cancer is preventable, if people eat more fruits and vegetables, more legumes and grains, less red meat, salt and saturated fat (Cedar, 2001).

Pulses are not presented as having any particular advantage, compared to other plant foods, against cancer: they are low in fat and rich in dietary fibre. Dietary fibre is not presented as a key factor for cancer prevention either, since recent studies suggest that fibre alone does not protect against cancer. It is rather the plant material as a whole, containing fibre, vitamins, minerals and phytochemicals, that works to lower the cancer risk in many ways (American Institute for Cancer Research, 2001a).

\section{Diabetes}

People suffering from diabetes must control their glycaemia, i.e. their blood glucose concentration. The glycaemic index, which expresses the relative ability of different foods to raise the level of glucose in blood, helps them to choose the sources of carbohydrates that provide a slow release of glucose after a meal. Among the numerous starchy foods available, beans, and pulses in general, present the lowest glycaemic index, which makes them a valuable source of energy for diabetic people. For example, the glycaemic index of kidney beans does not exceed 27 (glucose $=100$ ), and those of lentils and chickpeas, 28 and 33, respectively, whereas those of rice, wholemeal bread and baked potatoes reach 50, 77 and 85, respectively (FosterPowell \& Brand-Miller, 1995).

This advantage is not highlighted by diabetes associations. Rather, the latter recommend, as does the AICR, choosing a diet containing plenty of grain products, vegetables and fruit and to avoid sugary foods, fat, salt and alcohol (American Diabetes Association, 2001; Diabetes UK, 2001a).

On its ideal plate, Diabetes UK (2001b) puts beans and other pulses in the 'protein' group, together with meat and fish, and considers bread, cereals and potatoes as starchy foods. The American Diabetes Association, however, puts pulses in with the 'grains, beans and starchy vegetables' at the bottom of its food pyramid but also presents them as a possible substitute for meat. It means that people are advised to eat more grains and beans than any other foods. It is also recommended that diabetic people eat more starches, whatever their origin. Foods suggested to increase starch intake are grains and pulses, the latter in the form of soups or salads. Glycaemic regulation is seldom mentioned.

\section{Coronary heart disease}

Coronary heart disease (CHD) is, in most industrialized countries, one of the most common single cause of death. There is strong evidence that nutritional factors contribute to the aetiology of the condition and that dietary modification, together with life-style modification, are important in the treatment of patients (Mann \& Truswell, 1999). A positive correlation has been established between CHD death rate and plasma cholesterol level, and, among other things, the latter is due to too high a consumption of saturated fat. On the other hand, a regular intake of beans, or any other pulse, may contribute to lowering of the plasma cholesterol level (Anderson et al., 1984; Shutler et al., 1989; Kingman, 1991).

This positive effect of pulses is not mentioned by the American Heart Association (2001a) nor by the Vegetarian Resource Group (2001), which suggests heart-healthy diets. As for cancer and diabetes, the new message is: 'eat more plant-based foods', rather than 'avoid saturated fat and cholesterol'. The basis of the recommendations is a diet rich in fruits, vegetables, legumes (beans), whole grains, low-fat dairy products, fish and lean meat (American Heart Association, 2001a). In the food guide pyramid for people at risk with $\mathrm{CHD}$, beans are included in the bottom portion, together with bread, cereals and starchy vegetables (American Heart Association, 2001b) but not as a substitute for meat products.

The Heart Information Network, however, presents and explains the components of beans that help reduce $\mathrm{CHD}$ or cancer risks. Beans are first presented as a source of soluble fibres that lower blood levels of cholesterol, and 
a poor source of fats, especially saturated ones (Grieger, 2001a). Beans, together with peas, lentils and chickpeas, are also shown as the best sources of folate, the vitamin that lowers the blood level of homocysteine. High levels of homocysteine are associated with an increased risk of heart disease (Grieger, 2001a; Newgent, 2001). They are also seen as a poor source of fat. Finally, Grieger $(2001 b)$ presents beans as a valuable source of phytochemicals that are good for health. For example, they contain saponins that knock out some kinds of tumour cells, particularly lung and blood cancers. These phytochemicals also lower blood cholesterol by inhibiting either cholesterol absorption or bile acid reabsorption. Isoflavones, found in chickpeas, lower blood cholesterol and have antioxidant effects.

\section{Obesity}

Overweight and obesity are a main concern for an increasing number of people in the world, and are associated with the risk of a wide number of diseases and health disorders. They have a multiple origin and the most obvious is certainly the amount of food eaten.

The associations for overweight and obese people do not propose a list of diets that help reduce body weight but rather inform them on the possible health consequences, on how to change their life-style, etc.

Therefore, advice on the advantage of specific foods are not provided and pulses are scarcely mentioned. In one case, people are advised to eat as their ancestors did, i.e. either as Stone-Age ancestors, who consumed primarily plants such as nuts, grains, beans and fruits, or, more recently, as early 20th-century ancestors, whose diet was based on carbohydrates (bread, beans) and not on fat (Obesity.com, 2001). The Heart Information Network also mentions the bulk properties of beans, which help increase fullness after the meal and are useful in weight-reduction plans (Grieger, 2001a). Finally, most health organizations advise a lowering of body weight and present the plantbased food diet as the best way to success.

\section{Others}

The US Department of Agriculture recently published the most recent edition of its Dietary Guidelines for Americans (United States Department of Agriculture, 2000). It is based on the classic food pyramid guide, in which beans are presented in the 'meat, fish, dry beans, eggs and nuts' group, i.e. the protein group. However, in a footnote, it is specified that dry beans, peas and lentils can be counted as servings in either the meat and bean group or in the vegetable group.

The American Dietetic Association (2001) also provides advice in its food and nutrition guide, but beans are only mentioned as a good fibre source.

Other associations, such as Oldways Preservation and Exchange Trust (2001), promote the Mediterranean diet, i.e. the standard diet consumed in most of the countries surrounding the Mediterranean Sea, which has been seen as the main factor explaining why people in this region enjoy among the lowest rate of chronic disease and the highest adult life expectancy in the world. When the diet is presented in a food pyramid form, beans are included in the second most important group that should be consumed daily, i.e. the 'fruit, vegetables, beans, legumes and nuts group'. The most important group is that of bread and starchy food. In this case, fish, poultry and eggs should be consumed weekly and red meat monthly. Beans are thus presented as a staple food.

\section{Discussion}

Most of the health organizations, as well as the US Department of Agriculture, have recently updated their message on dietary guidelines. Warnings on saturated fat sources or on amounts of salt allowed are no longer mentioned. The message is simplified: 'eat more plant-based foods'. Pulses are presented, together with cereals, as whole grains, i.e. raw foods rich in complex carbohydrates, minerals and vitamins. Their supposed or demonstrated advantages in lowering the risks for $\mathrm{CHD}$, diabetes or cancer are not mentioned specifically by these organizations, with the exception of the Heart Information Network. However, pulses always appear highlighted in the advice column and food pyramid guides, which are obviously preferred means of communication.

These positive campaigns, based on the promotion of traditional cuisine rather than on fear of any disease, will probably have a better impact on people. This long-term education programme might receive better attention from people concerned about their health but who have no basic knowledge of nutrition. In the United States, pulse consumption has increased during the past years, thanks to the Hispanic community, and now reaches $3.6 \mathrm{~kg} /$ capita per year (Lucier et al. 2000). In the European Union, pulse consumption has also increased by $34 \%$ during the past 10 years, to $3.9 \mathrm{~kg} / \mathrm{capita}$ per year, even if differences between countries are still large (FAOSTAT, 2001). These encouraging data indicate a revival of interest in pulses. If their image could be associated with health, these trends could be accelerated in the future.

\section{Conclusion}

Recently, the health organizations have changed their message to the consumer. They no longer provide advice and recipes to reduce blood cholesterol level or regulate glycaemia but rather promote the increase in plant-based food consumption, especially whole grains, in order to take advantage of the joint effect of their different components. In this way, pulses are seen as a staple food because they are nutritious and provide most of the ingredients that help to improve health (complex carbohydrates, minerals, etc.). This could encourage more consumers who are concerned about their health to consider eating pulses more frequently.

\section{References}

American Diabetes Association (2001) Eating healthy with the 
diabetes food pyramid as your guide. http://www.diabetes.org/ main/health/nutrition/article031799.jsp

American Dietetic Association (2001) Food and Nutrition Guide Excerpts. http://www.eatright.org/adafood.html

American Heart Association (2001a) Dietary guidelines for healthy American adults. http://www.americanheart.org/ Scientific/statements/1996/1001.htm

American Heart Association (2001b) Delicious decisions: the AHA food pyramid. http://www.deliciousdecisions.org/ee/afp. html.

American Institute for Cancer Research (1997) Food, Nutrition and the Prevention of Cancer: A Global Perspective. Washington: American Institute for Cancer Research Publications.

American Institute for Cancer Research (2001a) Diet and Cancer Report. http://www.aicr.org/report2.htm

American Institute for Cancer Research (2001b) The New American Plate booklet. http://www.aicr.org/NAPbook.htm

Anderson J, Story L, Sieling B, Chen W, Petro M \& Story J (1984) Hypocholesterolaemic effects of oat bran or bean intake for hypercholesterolaemic men. American Journal of Clinical Nutrition 40, 1146-1155.

Barasi M (1997) Human Nutrition: A Health Perspective. Oxford: Oxford University Press.

Cedar D (2001) Eating well for cancer prevention. http://www. wellnessweb.com/nutri/eating_well_for_cancer_preventio.htm

de Puytorac P (2000) Biotechnologies: conséquences socio-économiques (Biotechnologies: socio-economical consequences). L'Année Biologique 39, 123-204.

Diabetes UK (2001a) Six steps to healthy eating with diabetes. http://www.diabetes.org.uk/manage/eatwell/steps.htm

Diabetes UK (2001b) An ideal plate-balancing food proportions correctly. http://www.diabetes.org.uk/manage/eatwell/plate.htm

FAOSTAT (2001) FAOSTAT Database. Food supply: crop primary equivalent. http://apps.fao.org/page/collections?subset= nutrition

Foster-Powell K \& Brand-Miller J (1995) International tables of glycemic index. American Journal of Clinical Nutrition 62, Suppl., 871S-893S.

Geil PB \& Anderson JW (1994) Nutrition and health implications of dry beans: a review. Journal of the American College of Nutrition 13, 549-558.

Grieger L (2001a) Nutrition guide: bean cuisine for the heart.
Heart Information Network. http://www.heartinfo.org/ nutrition/bean061099.htm

Grieger L (2001b) Nutrition guide: phytochemicals and legumes. Heart Information Network. http://www.heartinfo.com/ nutrition/phytochem031700.htm

Kingman S (1991) The influence of legume seeds on human plasma lipid concentrations. Nutrition Research Reviews 4, 97-123.

Lucier G, Lin BH, Allshouse J \& Scott Kantor L (2000) Factors affecting dry bean consumption in the United States. Vegetables and Specialities 280, 26-34.

Mangels R (2001a) Protein in the vegan diet. The Vegetarian Resource Group: Nutrition. http://www.vrg.org/nutrition/ protein.htm

Mangels R (2001b) Iron in the vegan diet. The Vegetarian Resource Group: Nutrition. http://www.vrg.org/nutrition/iron.htm

Mann J \& Truswell S (1999) Essentials of Human Nutrition. Oxford: Oxford University Press.

Messina V \& Burke K (1997) Position of the American Dietetic Association: vegetarian diets. Journal of the American Dietetic Association 97, 1157-1159.

Newgent J (2001) Nutrition guide: is folate on your plate? Heart Information Network. http://www.heartinfo.org/nutrition/ folate4398.htm

Obesity.com (2001) Eating for health. Forward into the past: eating as our ancestors did. http://www.obesity.com

Oldways Preservation and Exchange Trust (2001) The traditional healthy Mediterranean Diet Pyramid. http://www.oldwayspt. org/html/mediterr.pyramid.htm

Shutler S, Bircher G, Tredger J, Morgan L, Walker A \& Low A (1989) The effect of daily baked bean (Phaseolus vulgaris) consumption on the plasma lipid levels of young, normocholesterolaemic men. British Journal of Nutrition 61, 257-265.

United States Department of Agriculture (2000) Dietary Guidelines for Americans. Washington DC: USDA Publications.

Vegetarian Resource Group (2001) Heart Healthy Diets: the Vegetarian Way. Vegetarianism in a Nutshell. http://www.vrg.org/ nutshell/heart.htm

Vegetarian Society UK (2001a) 21st Century Vegetarian: Basic Nutrition. http://www.vegsoc.org/news/2000/21cv/nutrition/html

Vegetarian Society UK (2001b) Information sheet: pulses. http:// www.vegsoc.org/info/pulses.html 